\section{Should There Be a Cap on the Number of Patients Under the Care of a Clinical Pharmacist?}

\section{THE "PRO" SIDE}

In the ideal health care system, there would be an abundance of resources to ensure timely and comprehensive patient care. However, it is a well-known reality that demands on Canadian hospitals and clinical pharmacy services are escalating because of increases in the number of elderly patients, the acuity of patients' conditions, the complexity of drug regimens, and the length of stay in hospital. In addition, there continues to be a shortage of hospital pharmacists. Despite these challenges, patient care should not be compromised. Hence, we believe that there should be a cap on the number of patients under the care of a clinical pharmacist. We outline here the 4 main reasons for this position.

First, not limiting the number of patients under the care of a clinical pharmacist may compromise patient care and may actually increase costs. The value of clinical pharmacy services is well documented in the literature, ${ }^{1-15}$ and certain interventions such as participation in patient care rounds and inservice education have been shown to decrease mortality. ${ }^{1-3}$ If individual pharmacists are each expected to take care of a large number of patients, it may not be possible for them to perform all of these mortality-reducing interventions for all assigned patients. ${ }^{15}$ Furthermore, Bond and $\mathrm{Raehl}^{3}$ have demonstrated an association between the number of pharmacists per 100 beds and mortality. In addition, when pressed for time, pharmacists may only deal with urgent issues or troubleshoot problems and may not consistently perform certain cost-saving activities such as development and management of drug protocols, making switches from IV to oral dosage forms, or changing therapy to less expensive alternatives.

Second, a heavy patient load may be detrimental to the pharmacist's relationship with other health care professionals. If the pharmacist has an excess number of patients to see, he or she may be forced to provide targeted services to patients at various locations in an institution and may thus be unable to develop consistent relationships with the other health care professionals on the patient care team. The value of the pharmacist is realized when he or she practises in a collaborative, integrated environment and when other health care professionals can place a face to a name. Pharmacists are more likely to be consulted if they are present in person than if they have to be paged or called. Scaling back services may suggest to other health care professionals that pharmacists are only capable of targeted tasks, such as recommending drug dosages, rather than being medication experts who are capable of comprehensive assessments of medication therapy. As a result, the level of trust between the pharmacist and other members of the health care team will be lower, which may in turn mean that the pharmacist practises at less than the optimal scope, hence jeopardizing the growth of the pharmacy profession.

Third, other health care professions are using caps on patient numbers to deal with the strain of increasing demand for their services. It is well accepted that a general practitioner will stop accepting new patients or that patients will wait several months to obtain care from a specialist because the physician has capped the patient load to a prespecified number of patients per day. ${ }^{15}$ Physicians do not compromise the quality of their patient care through excess patient load, and neither should pharmacists. Patients and other health care professionals should be able to expect the same high-quality pharmaceutical care from any clinical pharmacist in any institution. To meet this expectation, we need to limit the number of patients under each pharmacist's care, because each comprehensive assessment requires a finite period of time to perform, and each pharmacist has only a finite number of working hours per day. If other health care professionals were to limit themselves to "troubleshooting", as pharmacists do when patient load is excessive, it would be the equivalent of a nurse only checking vital signs or a cardiologist only reading electrocardiograms when they see a patient, neither of which would be acceptable. For pharmacists to be utilized to their maximum scope, we need to align our work with all of the patient's medication-related goals, not just some of them.

Finally, not instituting a patient cap can have a detrimental effect on pharmacists' job satisfaction. An increasing number of patients causes the pharmacist's daily routine to be increasingly "task-oriented". This is an ironic situation, given that the majority of pharmacists choose this profession because they want to help people. Not being utilized to their maximum potential will reduce job satisfaction, and pharmacists who choose to remain in such environments will eventually lose their holistic patient assessment skills, which is detrimental to both patients and the future of clinical pharmacy. We need pharmacists who are passionate about and actively engaged in patient care to advance the profession to its maximum scope of practice.

In conclusion, it is a long-term goal of the profession for pharmacists to deliver consistent pharmaceutical care for each of their patients. In the presence of limited resources, it is imperative that the quality of patient care not be compromised in order to provide consistent but substandard care. There should definitely be a limit or cap on the number of patients under the care of a clinical pharmacist. Unlike other health care 
professionals, the optimal pharmacist-to-patient ratio is still unknown; this should be an area for future research and exploration.

\section{References}

1. Bond CA, Raehl CL, Pitterle ME, Franke T. Health care professional staffing, hospital characteristics, and hospital mortality rates. Pharmacotherapy 1999;19(2):130-138.

2. Bond CA, Raehl CL, Pitterle ME. Staffing and the cost of clinical and hospital pharmacy services in United States hospitals. Pharmacotherapy 1999; 19(6):767-781.

3. Bond CA, Raehl CL. Clinical pharmacy services, pharmacy staffing, and hospital mortality rates. Pharmacotherapy 2007;27(4):481-493.

4. Bond CA, Raehl CL. Clinical pharmacy services, pharmacy staffing, and adverse drug reactions in United States hospitals. Pharmacotherapy 2006; 26(6):735-747.

5. Cohen V, Jellinek SP, Hatch A, Motov S. Effect of clinical pharmacists on care in the emergency department: a systematic review. Am J Health Syst Pharm 2009;66(15):1353-1361.

6. Jenkins $\mathrm{MH}$, Bond CA. The impact of clinical pharmacists on psychiatric patients. Pharmacotherapy 1996;16(4):708-714

7. Kaboli PJ, Hoth AB, McClimon BJ, Schnipper JL. Clinical pharmacists and inpatient medical care: a systematic review. Arch Intern Med 2006;166(9):955-964.

8. Kopp BJ, Mrsan M, Erstad BL, Duby JJ. Cost implications of and potential adverse events prevented by interventions of a critical care pharmacist. Am J Health Syst Pharm 2007;64(23):2483-2487.

9. MacLaren R, Bond CA, Martin SJ, Fike D. Clinical and economic outcomes of involving pharmacists in the direct care of critically ill patients with infections. Crit Care Med 2008;36(12):3184-3189.

10. Makowsky MJ, Koshman SL, Midodzi WK, Tsuyuki RT. Capturing outcomes of clinical activities performed by a rounding pharmacist practicing in a team environment. The COLLABORATE Study. Med Care 2009; 47(6):642-650.

11. McMullin ST, Hennenfent JA, Ritchie DJ, Huey WY, Lonergan TP, Schaiff RA, et al. A prospective, randomized trial to assess the cost impact of pharmacist-initiated interventions. Arch Intern Med 1999;159(19): 2306-2309.

12. Perez A, Doloresco F, Hoffman JM, Meek PD, Touchette DR, Vermeulen LC, et al.; American College of Clinical Pharmacy. ACCP: economic evaluations of clinical pharmacy services: 2001-2005. Pharmacotherapy 2009;29(1):128.

13. Schumock GT, Butler MG, Meek PD, Vermeulen LC, Arondekar BV, Bauman JL; 2002 Task Force on Economic Evaluation of Clinical Pharmacy Services of the American College of Clinical Pharmacy. Evidence of the economic benefit of clinical pharmacy services: 1996-2000. Pharmacotherapy 2003;23(1):113-132.

14. Gorman S, Heukshorst S. Should pharmacy technicians provide clinical services or perform patient care activities in areas without a pharmacist? The "con" side. Can J Hosp Pharm 2010;63(5):392-394.

15. Jorgenson D. Should clinical pharmacist resources be equally distributed across an institution to ensure a consistent level of clinical service for all patients? The "con" side. Can J Hosp Pharm 2007;60(3):206-207.

Erica H Z Wang, BScPharm, PharmD, ACPR

Clinical Pharmacy Specialist - Cardiology

Kelowna General Hospital

Interior Health Authority

Kelowna, British Columbia

Michelle Co, BScPharm

Pharmacy Resident

Lower Mainland Pharmacy Services - Fraser Pod

Vancouver, British Columbia

\section{THE "CON" SIDE}

Clinical pharmacists perform various activities that help to optimize patients' medication therapy. However, the full impact of clinical pharmacists may not be realized, given ever-increasing patient acuity and pharmacist workload in the setting of limited resources. Therefore, pharmacy leadership is constantly looking for ways to help meet the demands of the health care system. There are a number of strategies that may be employed to help with the pharmacy workload, but instituting a patient cap system - which involves limiting the number of patients under the care of a clinical pharmacist - should not be considered.

For a number of reasons, a patient cap system would be difficult to implement. First, pharmacy leadership would have to determine the ideal pharmacist-to-patient ratio. Those in favour of the patient cap system will typically refer to a study by Bond and Raehl ${ }^{1}$ to support their argument. However, that study had significant methodological flaws that limit its applicability. The results were based on self-reported hospital data, which may be biased and inaccurate. In addition, the study methodology was suitable for inferring an association, not causality, since the mechanism of how the work of pharmacists decreases mortality could not be elucidated. Furthermore, the study was conducted in US hospitals, with end points based on patients admitted to general medicosurgical hospitals, which limits its applicability to Canadian institutions and other types of patient care units. Beyond the limitations of the Bond and Raehl study, ${ }^{1}$ a single pharmacist-to-patient ratio cannot be applied to all types of practice settings: for example, the ratio for a pharmacist practising on a general medicine ward would be different from that for a pharmacist on an intensive care unit and vice versa. Therefore, individual, practice-specific ratios would be required for each type of patient care unit to make the patient cap system feasible. Unfortunately, we do not have the data that would be needed to determine the ideal ratio for various practice areas.

Second, clinical pharmacists will likely view the strategy of capping the number of patients as an ethical dilemma, and it would be difficult for pharmacy leadership to enforce the system. Pharmacists are autonomous caregivers and may use their professional judgment to disregard a patient cap in favour of providing appropriate patient care. To be sure, it would be beneficial for all pharmacists in an institution to adhere to the patient cap strategy, so that everyone's workload is reduced. However, not all clinical pharmacists will comply, and some will choose to provide care to patients beyond their capped number. Some would argue that it is unethical to provide clinical pharmacy services to certain patients on a particular ward but not others who may also have drug-related problems. Yet without full compliance from all pharmacists, the patient cap strategy will not work.

Finally, instituting a cap on patient numbers may have detrimental consequences for the pharmacy dispensary. Despite the evidence-based benefits of clinical pharmacy services, it must be kept in mind that the fundamental and essential pharmacy services in any institution involve providing patients with medications through the hospital medication distribution 
system. Whether or not there is a cap on the number of patients for individual clinical pharmacists, the distribution system is still required to run smoothly and efficiently. The dispensary is integral to identifying distribution-related issues and notifying the clinical pharmacist. If such issues are identified for patients not under the care of a particular clinical pharmacist, the dispensary pharmacist will have to resolve them. This increases workload, disrupts workflow, and may be detrimental to patient safety, as clinical decisions will be made in the dispensary, without full access to the patient's information. Also, if the dispensary workload is increased, clinical pharmacists will be pulled from their respective practice areas and asked to help, which ultimately (and ironically) results in a decrease in the provision of overall clinical pharmacy services in the institution.

We applaud the creative idea of setting a limit on the number of patients under the care of a clinical pharmacist. However, there seem to be more questions than answers at this point. When staffing and other resources are limited, we should be more focused on improving every clinical pharmacist's efficiency. Examples include reducing the amount of time that clinical pharmacists spend on noncognitive duties and ensuring that evidence-based clinical services are provided.

\section{References}

1. Bond CA, Raehl CL. Clinical pharmacy services, pharmacy staffing, and hospital mortality rates. Pharmacotherapy 2007;27(4):481-493.

Damen Man, BScPharm, ACPR, PharmD

Pharmacist, Critical Care and Pharmacy Departments

Toronto Western Hospital, University Health Network

Toronto, Ontario

Vincent H Mabasa, BScPharm, ACPR, PharmD

Coordinator, Clinical Pharmacy Services

Lower Mainland Pharmacy Services

Fraser Health I Providence Health Care I Provincial Health Services

Authority I Vancouver Coastal Health

Clinical Assistant Professor

Faculty of Pharmaceutical Sciences

The University of British Columbia

Vancouver, British Columbia

CSHP has introduced both Print and Print + Online pricing models for CJHP subscriptions. Print + Online CJHP is included as a benefit of CSHP membership. All prices are in Canadian funds.

La SCPH a établi une grille tarifaire pour l'abonnement à la copie imprimée du JCPH seulement et pour l'abonnement à la fois aux copies imprimée et électronique du journal. L'abonnement combiné est inclus dans les droits d'adhésion à la SCPH. Tous les prix sont en dollars canadiens.

\begin{tabular}{|l|l|l|}
\hline $\begin{array}{l}\text { Subscriber group / Groupe } \\
\text { d'abonnés }\end{array}$ & $\begin{array}{l}\text { Print only / Texte imprimé } \\
\text { seulement }\end{array}$ & $\begin{array}{l}\text { Print + Online copy } \\
\text { Texte imprimé } \\
\text { et exemplaire électronique }\end{array}$ \\
\hline $\begin{array}{l}\text { Nonmembers within Canada / } \\
\text { Non-membres au Canada }\end{array}$ & $\begin{array}{l}\$ 110.00 \text { per year, plus GST or HST } \\
110,00 \$ \text { par an, plus TPS ou TVH }\end{array}$ & $\begin{array}{l}\$ 150.00 \text { per year, plus GST or HST } \\
150,00 \$ \text { par an, plus TPS ou TVH }\end{array}$ \\
\hline USA / É.-U. & $\begin{array}{l}\$ 140.00 \text { per year } \\
140,00 \$ \text { par an }\end{array}$ & $\begin{array}{l}\$ 180.00 \text { per year } \\
180,00 \$ \text { par an }\end{array}$ \\
\hline Foreign / Étranger & $\$ 180.00$ per year & $\$ 220.00$ per year \\
& $180,00 \$$ par an & $220,00 \$$ par an \\
\hline
\end{tabular}

More details can be found at www.cjhp-online.ca. If you would like to purchase a subscription, please fill out our CJHP 2012 Subscription Application Form, which can be found on the CJHP website.

Please direct any comments or questions to Colleen Drake, Publications Administrator,

at cdrake@cshp.ca.

Des détails supplémentaires sont fournis à www.cihp-online.ca. Si vous désirez vous abonner, veuillez remplir le formulaire d'abonnement au JCPH 2012. Vous pouvez l'obtenir en visitant le site Web du $\mathrm{JCPH}$. Pour tout commentaire ou toute question, veuillez vous adresser à Colleen Drake, agente des publications, en écrivant à cdrake@cshp.ca. 